\title{
EXPLORING THE FOUNDATIONAL ORIGINS OF PUBLIC SERVICE MOTIVATION THROUGH THE LENS OF BEHAVIORAL GENETICS
}

Despite the proliferation of research on public service motivation (PSM), fundamental questions about its origins continue to evade scholars: Is PSM driven by genetics, socialized through experiences, or both? If PSM is socialized, when does socialization occur? Answering these questions is critical for reconciling the state $v$ s trait debate, and for assessing the validity of practical implications prescribed by PSM studies. Utilizing "nature's own experiment", we adopt a classical twin-design with 1,035 twin pairs to identify how genetic heritability, a common environment, or unique environment and experiences can explain variation in PSM. Results show that PSM is heavily influenced by individuals' unique environments and experiences; not by genetics. This lends strong evidence to PSM's uniqueness as a motivational construct as related "other-regarding" concepts show sizeable genetic components. Finally, our results corroborate that PSM is a human resource with dynamic properties organizations can cultivate to enhance productivity in public service workforces.

Keywords: Public service motivation, genetics, socialization, twins, natural experiment.

Cite as*:

Florczak, C., Rasmussen, S. H. R., Jensen, U. T., Stritch, J. M., Christensen, K., Nørgaard, A. S., \& Klemmensen, R. (2022). Exploring the Foundational Origins of Public Service Motivation through the Lens of Behavioral Genetics. Online before print in Public Administration. https://doi.org/10.1111/padm.12837.

*This is the accepted version, and content may therefore not perfectly represent the published version. Please consult the published version at: https://doi.org/10.1111/padm.12837. 
Public service motivation (PSM) research continues to generate a vast literature on everything from antecedents (e.g., Kim 2020; Perry 1997; Pandey and Stazyk 2008;

Witteloostuijn, Esteve, and Boyne 2017) to its effects on individual behavior and performance (e.g., Andersen, Heinesen, and Pedersen 2014; Jensen \& Vestergaard, 2017). Despite this progress, enduring questions continue to haunt PSM research: Is PSM a stable trait - a “predisposition" as originally suggested by Perry and Wise (1990)? - or is it dynamic and malleable?

These questions are at the heart of the dominant - yet often implicit - assumption of most empirical PSM research: PSM is a human resource that can be fostered to enhance productivity of public sector workforces (e.g., Christensen, Paarlberg, and Perry 2017). While few may regard this assumption as controversial, merely adopting an axiomatic assumption that PSM is dynamic hampers our ability (1) to advance conceptual understandings of PSM and (2) to legitimately claim practical recommendations on its applications. If PSM is a predominantly stable trait with a sizeable genetic component or heavily influenced by early childhood socialization, organizations are confined to harnessing its power through selection and recruitment processes. Conversely, if PSM is dynamic and malleable, identifying potential ways that family, education, and organizational environments can cultivate this resource through socialization processes should remain a key objective.

To help close this critical and fundamental gap in the PSM literature, we offer several contributions to PSM theory and research. First, while the "state $v s$ trait" debate is not new (Wright and Grant 2010), its continuous resurfacing (e.g., Jensen et al., 2020) stresses the pressing need to resolve this conundrum. This has important implications for both PSM theory and the practical recommendations flowing from it. An important part of advancing PSM theory 
is disentangling its conceptual roots and demonstrating its uniqueness from other, related "otherregarding" constructs. One way to demonstrate conceptual distinctiveness of PSM is to showcase its discordant properties from constructs such as altruism, emphathy, and pro-sociality that all have sizeable genetic components. Second, even if PSM is rooted in socialized environments and experiences, these may occur either early or later in life creating more stable or volatile properties. Tracing the roots of PSM and parsing early $v s$ later-in-life socialization is an important precondition for advancing PSM theory. Finally, providing rigorous empirical evidence to assess the validity of the axiomatic assumption that PSM is dynamic offers legitimacy to the large existing body of work that prescribes a host of practical recommendations on ways to cultivate PSM in public service workforces.

Our article is structured as follows. First, we introduce how the field of behavioral genetics affords us a unique opportunity to advance fundamental insights into the conceptual origins of PSM. Next, we show how existing research have explored the role of environmental factors for PSM, but has neglected to investigate potential genetic origins. We then formally introduce our model, which allows us to trace genetic origins of PSM by parsing its variance into three components: Genetic, common environment and unique environment. In the results section, we demonstrate that PSM entails no heritable components but manifests and develops as a function of environmental factors. We conclude the article with a discussion of implications and propose that the literature's current focus on debating "stable trait" vs "dynamic state" of PSM is obfuscating the more important issue of identifying which mechanisms help solidify and which mechanisms help create change in PSM.

\section{EXPLORING FOUNDATIONAL ORIGINS OF PUBLIC SERVICE MOTIVATION:}




\section{HOW DOES BEHAVIORAL GENETICS HELP US?}

\section{Behavioral Genetics}

Operating at the crossroads between biology and the social sciences, behavioral genetics considers individual differences in attitudes and behaviors using methodologies commonly applied in genetics research (Medland and Hatemi 2009). Much behavioral genetics is considered basic research as it seeks to advance theories by understanding the very nature of social phenomena. While this way of advancing theory differs from most empirical PSM research which attempts to establish associations between a predictor $(\mathrm{x})$ and an outcome $(y)$, understanding PSM's genetic and social origins is a foundational precursor for any applied research on PSM's practical value for public service workforces and productivity.

A tenet of the behavioral genetics tradition for understanding the nature of social phenomena concerns separating the effects of genetic variation from effects of social variation. This prevents genetic variation from confounding correlations between social phenomena. The most common method for achieving this separation is the "classical twin design". This design relies on decomposing variance in a phenotype. A phenotype refers to an observable, measurable characteristic of an individual. In the language of behavioral genetics, PSM is the phenotype of interest in our study.

While we discuss the design in detail in our methods section, examining variation within twin pairs (i.e., among "co-twins") and between the MZ and DZ twin pairs, we can decompose variation into three components. These components are commonly referred to as additive

genetics (or A), common environment (or C) and unique environment (or E) (Bouchard and 
McGue 2003). Additive genetics (A), as the term states, refers to heritability of a phenotype as a function of additive genetic components. The common environment (C) refers to conditions shared by co-twins such as their upbringing and early childhood experiences, including family environment and parental socialization. Finally, the unique environment (E) refers to a broad cluster of environmental conditions uniquely experienced by a twin such as attributes of one's job, workplace or social life.

We seek to advance PSM theory by decomposing the full range of variance in our measure of PSM and explore the extent to which the origins of PSM can be attributed to the three sources of variation. To be clear, our aim is not to disentangle the relative empirical merits of specific types of environmental conditions within each of these broader categories (e.g., relative importance of job attributes vs. management practices; parental influence vs. elementary education). Rather, we break down the entire variance in PSM to understand whether it manifests primarily as a function of heritable, genetic components, of common (often shared family) environmental conditions, or of unique (often later-in-life) environmental conditions; or a mix of the three.

Exploring the foundational origins of PSM enables us to advance theories of PSM in multiple ways. First, understanding the origins of PSM and its true sources of variance is a prerequisite for generating and advancing theories on PSM's manifestation and development. Without the basic knowledge into PSM's origins, we risk generating theories that attribute environmental conditions as causes of PSM when, in fact, these conditions merely disguise underlying selection effects based in deeper-rooted factors with strong genetic components. Studies on the role of education for individuals' PSM is a prime example (e.g., Bright 2005; Perry 1997; Kim 2020). If we observe that individuals with higher levels of educational 
attainment also express higher PSM, does that mean education acts as environmental condition shaping individuals' PSM? Maybe. If PSM has a sizeable heritable component, education and PSM could both be a function of certain predispositions mediated by an individuals' intelligence and/or constellation of personality traits.

Second, understanding the origins of PSM enables us to offer more nuanced and conclusive evidence on whether PSM consists of mostly stable (e.g., trait-like) or dynamic features (Wright and Grant 2010). It is important to note that we do not adopt a dichotomous view of PSM as either a fully stable trait or a completely fluid state. Stability in PSM can be deep-rooted as a function of the one-shot genetic "lottery" that everyone gets to play once. If PSM is highly heritable, this deep-rooted stability limits the potential for socializing environmental conditions to shape PSM, and might confound apparent associations between socializing factors and PSM as discussed above. However, PSM can also appear stable even without a considerable genetic component. If variation in PSM is mostly due to early childhood socialization processes, its manifestation will appear as "stable" later in life, and certainly fall outside the realm of managers' or organizations' discretion to influence. Lastly, observed stability can also be a consequence of time invariance in social influences that can in principle be changed, such as an individual's work environment.

By adopting the classical twin design, we not only contribute to the debate on whether PSM is mostly stable or dynamic, but we go one step further and rethink how this debate is shaped. Rather than focusing on labeling PSM as either stable or dynamic, we shift the debate towards an examination of the mechanisms leading to stable or dynamic construct behavior and recognize that aspects of the PSM construct might be both stable and dynamic. 


\section{Genetics and PSM}

The case for investigating a possible genetic component of PSM is based on several observations from the literatures on public administration, behavioral genetics, and psychology. One observation comes from the ongoing conceptual debate in the public administration community regarding the content of the PSM construct. Several definitions of PSM have drawn on 'other-regarding' concepts, such as altruism or sympathy (Bozeman and Su 2015). This has sparked a critique of PSM as being conflated with altruism (Ritz, Brewer, and Neumann 2016) or possibly too closely related to established concepts from other literatures (Vandenabeele, Brewer, and Ritz 2014). As a result, work has started to disentangle PSM from these 'other'regarding concepts (Schott et al. 2019; Piatak and Holt 2020).

Probing the literatures of these similar 'other'-regarding constructs, studies largely corroborate the notion of a genetic component to other PSM-like constructs. For instance, research on altruism often yields sizeable heritability estimates with more than 50 percent of individual-level variation in altruism attributed to genetics (Rushton et al. 1986; Koenig et al. 2007). Studies in psychology demonstrate genetic components either through twin studies or genome-wide association studies to concepts such as empathy (Warrier et al. 2018; Melchers et al. 2016), pro-sociality (Lewis and Bates 2011; Israel, Hasenfratz, and Knafo-Noam 2015), agreeableness (Vukasović and Bratko 2015; Bouchard and McGue 2003), and social justice and 
economic egalitarianism beliefs (Batrićević and Littvay 2017). ${ }^{1}$ It is also interesting to note that the antithesis to PSM - anti-social behavior - exhibits heritability as well (Moffitt 2005).

The expectation of a genetic component to PSM is substantiated when looking at PSM's prosocial outcomes. Several scholars have noted, that PSM is related to public service activities such as volunteering, charity and blood donations (Houston 2007; Clerkin, Paynter, and Taylor 2009); behaviors that have all been shown to be partly heritable (Pedersen et al. 2015; Son and Wilson 2010). In the workplace, PSM has been shown to affect job satisfaction and job interests. These too show heritable components ( Nofal et al. 2018). Additionally, Christensen and colleagues (2020) find a genetic component to sector choice. Since PSM has been linked to sector choice (Wright and Christensen 2010), both phenomena could share a common heritable component. Common outcomes predicted by PSM are thus likely to be influenced by genetics, and PSM might therefore also be construed as a mediating variable between genetics and the outcomes commonly emphasized in the existing PSM literature.

While the possibility of a genetic component to PSM has been mentioned in the literature (Van Witteloostuijn et al. 2017; Hamidullah, Van Ryzin, and Li 2016), it has yet to be investigated. Extant studies on PSM's emergence have largely focused on the role of different socialization processes and factors. We will now place PSM socialization into the behavioral genetics framework.

PSM Socialization and The ACE Model

${ }^{1}$ Empathy does have a few conflicting results in regard to a genetic component, see (Melchers et al. 2016) for a discussion. 
The main focus of the ACE model and classical twin design in the behavioral genetics tradition has been to disentangle genetic and social antecedents of behavior (Bouchard and McGue 2003). Researchers who used twin designs to investigate social phenomena knew that any given set of twins raised in the same household would be affected by two types of socialization processes (Powledge 1993). First, twins would have a series of shared experiences, which are often thought of as experiences that make twins more alike (Rutter 2002). In line with popular notions in psychological research from the 1960's (Plomin and Asbury 2005), this set of socialization processes, exemplified by parental and home environments, suggests that parents represent a core factor in explaining individual differences in traits and behaviors during childhood and adolescence (Rutter 2002). However, other types of shared environments between twins raised in the same household could be the neighbourhood or shared friend groups, and these environments could extend into adulthood. Second, twins are also influenced by their nonshared environment (Plomin and Daniels 1987), which is expected to make twins different from one another (Rutter 2002). These experiences are unique to each co-twin (Plomin 1990), and often consist of phenomena such as romantic relationships, work environment and later-in-life nuclear family environment. The classical twin design was thus introduced, not only to estimate genetic heritability of social phenomena, but also to disentangle the variation stemming from each of these two types of socialization processes.

Parental socialization is commonly thought to influence an individual's PSM (Perry 1997; Vandenabeele 2011; Stritch \& Christensen, 2016; Charbonneau and Van Ryzin 2017). As such, parents who have high PSM—or demonstrate a commitment to public service through their own public employment or voluntarism—can transfer these values to their children through 
socialization and modeling (Charbonneau and Van Ryzin 2017). Empirical findings tend to show that parental modeling and influence of public service or volunteering are positively associated with PSM and public service choices in their children (Perry 1997; Vandenabeele 2011). In twin pairs, we would expect parental socialization effects to be captured in PSM's variation attributed to the twins' common environment (C). This is a critical contribution of the ACE model as current research on the effects of parental socialization on PSM does not account or control for genetic factors.

Related to family socialization processes, scholars have considered both religious affiliation and participation as well as political beliefs and attitudes as possible factors affecting PSM. Perry and colleagues write, "Religion is among the most important cultural factors that give structure and meaning to human values, behaviors and experiences ... Altruistic behavior is a human ideal across most, if not all religions" $(2008,447)$. Perry argues that "religious foundational beliefs are related directly to several facets of public service motivation, specifically commitment to public interest/civic duty and compassion" $(1997,184)$. Political values and attitudes might be related to PSM in similar ways. As most scholars conceive it, conservative preferences towards markets, individual choice, and a limited role for government would drive negative associations between political conservatism and PSM. In contrast, those whose policy preferences are more to the left will be more supportive of governmental intervention and, thus, be more supportive of public service and have higher levels of PSM (Perry 1997; Vandenabeele 2011).

Unlike parental socialization, which remains a constant part of the common environment for co-twins of the same twin pair, the socialization of both political and religious values could come from the common environment (C) as well as the unique environment and unique 
experiences (E). Past behavioral genetics research does show varying results with regards to the effect of the $\mathrm{C}$ and $\mathrm{E}$ components on political ideology and religiousness (Hatemi et al., 2014; Hvidtjørn et al., 2013; Koenig et al. 2007), with the shared environment sometimes being completely absent as an antecedent and sometimes being a highly salient factor. In general, the common environment largely plays an insignificant role in many studies of political ideology due to the presence of a genetic (A) component. For religiosity, the common environment is often the largest contributor (sometimes explaining more than 70 percent of the variance depending on age), while genetics and the unique environment are of less importance.

Education is also considered an antecedent of PSM as educational institutions are thought to socialize values related to community membership and civic participation (Kim 2020; Perry 1997). The socialization effects of education on PSM could be captured in variation explained by either the common (C) or unique environment (E). Educational effects occurring in elementary or middle grades would likely be captured in the estimation of (C) so long as each twin was part of the same course of study. However, as co-twins grow older, they can opt-into different curricula. If co-twins opt-into different educational curricula in high school or college, the effects of different curricula on PSM would be captured in the variance explained by the unique environment $(\mathrm{E})$.

Researchers have also considered the role of organizational influence and socialization on an individual's PSM (e.g., Jensen and Bro 2018; Moynihan and Pandey 2007; Perry and Vandenabeele 2008; Wright, Moynihan, and Pandey 2012). For example, Moynihan and Pandey (2007) find that organizational red tape and the length of an individual's tenure in an organization both are negatively correlated with PSM, while the number of hierarchical levels in an organization and an organization's recent experience with personal reforms are found to be 
positively correlated with PSM. For the purpose of our study, we assume that workplace is part of an individual's unique environment and experiences, and that the cultivation and socialization of PSM in the workplace map onto the E component of the ACE model. By isolating the variation in PSM explained by the E component, we can better understand PSM's potential to be affected by HR interventions and shaped by institutional forces.

Based on the PSM literature, we expect social influences from the common environment (C) and unique environment (E) to explain variation in PSM. Critically important, however, is that no study of PSM has considered the role of social forces and influences while also accounting for genetic influences (A). The ACE model allows us to determine the extent to which socialization processes drive PSM variation without being confounded by genetic factors.

\section{RESEARCH DESIGN}

We adopt a classical twin design to estimate the extent to which PSM is influenced by genetic and environmental factors. The classical twin design (Neale and Cardon 1992) is a powerful tool for partitioning the relative contribution of heritable and environmental factors on PSM as it leverages the (dis)similarity of genetic material between two different types of twin pairs: Monozygotic (MZ or "identical") vs. dizygotic (DZ or "fraternal") twins. The design is based on an experimental logic. Rather than randomly assigning treatment conditions to subjects by the researcher, the classical twin design relies on what has been termed "nature's own experiment." (Segal 2010). The "condition" which systematically differs between the groups (i.e., MZ vs. DZ twins) is the degree of within twin-pair genetic similarity. During the "genetic lottery," a naturally occurring process randomly "assigns" conditions in the sense that MZ twins 
are born with identical genetic material, and thus share all (segregating) genes, while DZ twins share, on average, 50 percent of their segregating genes. ${ }^{2}$ As such, this naturally occuring process mimics controlled experiments through random assignment.

\section{Data}

Twin studies have slowly emerged in political science and management since the 1960's (Nofal et al. 2018), but they have developed a more prominent role in other social sciences such as psychology. While researchers have used such designs to study sector choice (Christensen, Moon, and Whitford 2020), to our knowledge, this study offers the first application of a twin design in public administration and management research to investigate PSM.

The Danish Twin Registry based at the University of Southern Denmark is the oldest nationwide register in the world and has collected information on Danish twins born in the last 150 years for a total of more than 85,000 pairs of twins (Pedersen et. al., 2019). Our data come from a series of surveys carried out by the Danish Twin Registry on a sample of co-twin pairs.

\footnotetext{
${ }^{2}$ Monozygotic (MZ) twins are frequently referred to as "identical twins" and are developed from the same egg fertilized by a single sperm cell. Whether embryo splitting after a single egg has been fertilized occurs or not is commonly accepted to be a random event characterized by chance. In contrast to MZ twins, dizygotic (DZ) twins, frequently referred to as "fraternal twins," are developed from two eggs fertilized by two different sperm cells. While the odds of having twins in the first place is partly a function of the mother's DNA, the similarity of within twinpair genetic materials is a product of chance, and thus mimics the random assignment to treatment process of controlled experiments.
} 
Wave 1 of the survey was conducted in 2009, Wave 2 of the survey was conducted in 2012, and Wave 3 was conducted in summer 2019. Our measures of PSM were captured in Wave 3 of the survey, and we utilize demographic data collected in Wave 1 to assess representativeness. In Wave 3, a total of 2,720 MZ and DZ twins were contacted with 1,342 twins responding for a response rate of 49 percent. The average age for both groups of twins are roughly similar with the MZ twins being 30.28 years old and the DZ twins 28.71, and the two groups are also similar in gender distribution with slightly more females than males participating for both twin types (see table 1). In addition to the initial invitation to participate in the study, two reminders were distributed to boost response rates.

\section{Measurement: PSM}

Twin registries are very valuable sources of information. As such, twins are highly sought after as respondents. We were therefore limited to including a few items to measure PSM. Specifically, we adopted the four-item global measure of PSM by Vandenabeele and De Vries (2016). The four items read: "I am very motivated to contribute to society", "I find it very motivating to contribute to society", "Making a difference in society, no matter how small, is very important to me", and "Defending the public interest is very important to me", and were recorded on a 5-point Likert scale ranging from "strongly agree" to "strongly disagree". Items were translated into Danish and embedded in the survey distributed in summer of 2019 (see appendix A).

Vandenabeele and De Vries $(2016,9)$ report a correlation of 0.74 between a scale based on the four items listed above and the multidimensional 16-item measure by Kim and colleagues (2012). This indicates the measures reflect the same underlying construct (Morrow 1983); a 
conclusion echoed by Wright, Christensen and Pandey (2013) in their study on the equivalence of global PSM measures. While we cannot disentangle the relative contribution of our global measure in reflecting individual dimensions of traditional PSM conceptualizations such as compassion, self-sacrifice or attraction to policy-making, it seems reasonable to expect that the measure covers individuals' general proclivity to contribute to a public interest and society at large. This motive has long been considered a foundational part of the PSM concept, and remains the locus of theories emphasizing the institutional bases of PSM (Vandenabeele 2007).

On this ground, we combine the four items by adding them together to an index, giving each indicator equal weight. We then rescaled the index to range from 0 to $1 .{ }^{3}$ The scale demonstrates adequate internal consistency with a Cronbach's alpha reliability score of 0.867 . Our approach for handling imputation and missing data is provided in appendix (B) as well as our assessment of representativeness.

\section{Estimating the ACE Model}

Prior to estimating the ACE model, we make an initial "screening" of the data to explore whether the mean and variances in PSM differ between female and male MZ and DZ twin pairs. If this is the case, analyses should be run for each of the four groups (female MZ and DZ, male MZ and DZ sepearately. If only mean PSM differs, we can collapse male and female MZ and DZ twin pairs, respectively, and include an indicator variable for gender to allow PSM to vary across the subgroups.

Twin model estimation is fairly intuitive if we think of correlation analysis. The unit of analysis is not an individual, but the correlation of PSM between co-twins. That is, how strongly

\footnotetext{
${ }^{3} x$ normalized $=(x-x$ minimum $) /(x$ maximum $-x$ minimum $)$
} 
correlated is the PSM of twins of the co-twin pair across MZ and DZ twins? If PSM of MZ cotwins is more strongly correlated than the PSM of DZ co-twins, heritability is likely at play. In fact, a preliminary estimate of heritability of PSM can be simply calculated by subtracting the difference between DZ and MZ correlations and multiply by 2. This technique is known as Falconer's formula in the behavioral genetics literature (Falconer \& MacKay, 1996). For example, if PSM is purely genetic, the DZ correlation would be 0.5 and the MZ correlation would be 1 ; yielding a heritability (A) estimate of $2 *(1-0.5)=1$. In other words, if MZ twins' PSM on average is more alike compared to DZ twins' PSM, then the difference can be attributed to the greater genetic similarity shared by MZ twins. In contrast, if we observe no within twinpair difference in PSM between MZ and DZ twins, we can rule out genetics or heritable components as sources of variation in PSM.

Since MZ twins share identical genetic material, correlation of PSM between MZ cotwins must be a function of an additive genetic factor (A) derived above plus the common environment shared by the co-twins (C). Since DZ co-twins share on average 50 percent of their genetic makeup, the role of the common environment can be calculated by subtracting the MZ correlation from two times the DZ correlation. For instance, if correlation of PSM between MZ and DZ twins are both 0.5 , then the estimate of common environment $(\mathrm{C})$ would be $2 * 0.5-0.5=$ 0.5 .

With A and C components derived, any remaining variance in PSM can be attributed to unique environment and experiences (E) to which each co-twin is uniquely exposed. The $\mathrm{E}$ component also includes the error term, suggesting that interpretation of this component should be conservative. Since MZ twins share 100 percent genetic material and have been exposed to the same common environment, any difference in PSM between MZ co-twins must be due to 
environmental factors unique to any individual co-twin, that is, the unique environment (E) (See Appendix C for a description of our SEM implementation).

\section{[FIGURE 1 HERE]}

\section{RESULTS}

Table 1 shows the descriptive statistics for the MZ and DZ twin pairs in our sample.

\section{[TABLE 1 HERE]}

To estimate the extent to which our measure of PSM displays an additive genetic component (A), we first run a set of simple correlations of PSM among the co-twins for the two groups (MZ and DZ) as reported in the Table 2. It is clear that these correlations do not differ substantially, indicating that a heritable component is low or negligible. If we compare the twin correlations for $\mathrm{MZ}$ and $\mathrm{DZ}$ twins, we see a difference of 0.026. A formal test of constraining the coefficients to equality cannot be rejected (Wald statistic $=1.648, \mathrm{df}=1 \mathrm{p}$-value $=0.199)$. If we use Falconer's formula, the estimated heritability would be $2 *(0.046-0.072)=-0.052$ (i.e. zero or very small). Given that the twin correlations for both $\mathrm{MZ}$ and DZ twin pairs are quite small, the role of common environmental factors also is quite small. Again, if we use Falconer's approach the influence of the common environment is estimated at $2 *(0.072)-0.046=0.098$; also quite low. 


\section{[TABLE 2 HERE]}

Next, we estimate the ACE model using the structural equation modeling approach outlined above. Results are displayed in Table 3 below. In line with the small heritability estimate above, the A component is essentially estimated to be close to zero. The unique environment (E), however, is highly significant. The unique environment (E) accounts for approximately 93 percent of the variance in PSM (squaring the standardized loading, $0.966^{2}=$ 0.933). PSM is thus not "trait-like" in the sense that it is explained by genetic differences. Second, this suggests that the unique environment (E) and nonshared experiences among twins, such as later in life socialization effects in a public sector setting might be crucial for explaining individual differences in PSM.

\section{[TABLE 3 HERE]}

A core feature of the ACE model is the ability to parse genetic heritability in the phenotype. Since our data indicates a negligible A component, we can increase statistical power by estimating a reduced form equation, focusing solely on the socializing $\mathrm{C}$ and $\mathrm{E}$ parameters. This is customary in behavioral genetics when no substantive heritability can be detected. A more formal test of model fit also suggest that the ACE model does not outperform a CE model, which is intuitive since the A components accounts for virtually no variance in PSM. Table 4 reports the estimates based on the reduced-form CE model. Squaring the factor loadings reported in tables 3 and 4, we note that common environment contributes between roughly 3 percent $\left(0.165^{2}=0.027\right)$ and 5 percent $\left(0.233^{2}=0.054\right)$ of the variance in PSM. As such, the substantive 
interpretation of our two models remain the same: the majority of the variance in PSM is due to the unique environment and experiences of an individual co-twin, while a limited portion of the variance can be attributed to co-twins common environment.

\section{[TABLE 4 HERE]}

\section{DISCUSSION}

The classical twin design provides insights into the emergence of an individual's PSM and offers multiple contributions to PSM research and theory. While investigating the relative effects of additive genetics (A), common environment (C), and unique environmental influences (E) on an individual's PSM is novel to public administration and public management, this approach is firmly anchored in the behavioral genetics tradition that untangles the effects of socialization processes from genetic influences on individuals' attitudes and traits (Blokland et al. 2013). The ACE model offers a unique perspective on the antecedent factors that drive PSM's development. PSM research has traditionally examined social influences, such as education and family experiences, by using them to predict PSM in bivariate or multivariate models (e.g., Bright 2005; Perry 1997; Stritch \& Christensen, 2016; also see Pandey and Stazyk 2008). While these correlational and cross-sectional studies suggest that social influences can be important drivers of PSM, they remain limited in several critical ways.

First, the effects of social factors in such models, such as parental influences and education, could be confounded by genetics. Given the importance of heritability in explaining other prosocial or 'other-regarding concepts' (Warrier et al. 2018; Melchers et al. 2016), it is 
critical to control for heritability when considering the effects of socialization processes on PSM. Second, to the extent PSM is socialized, the ACE model allows us to untangle common environmental (C) influence from those attributed to the unique environment (E). Furthermore, if PSM is the result of socialization processes, the approach helps us to understand when such socialization is likely to take place.

Examining the results of the ACE model, the effects of unique environment (E) were substantially larger than common environment (C), thus indicating that the relative importance in terms of explaining PSM tilts in favor of unique experiences. However, we note that in the ACE model, the error term is also captured by the E component of the model. As a result, an important consideration when interpreting the results is that the unique environment is likely inflated, and some caution is warranted as this is one limitation of the approach. Even so, the attribution of PSM to unique life experiences follows current theoretical accounts of PSM antecedents and supports the literature's focus on adulthood influences such as work environment as an important source of variation in PSM (e.g., Kjeldsen 2014; Jensen and Bro 2018; Moynihan and Pandey 2007; Wright, Moynihan, and Pandey 2012).

As our results suggest, however, PSM has virtually no genetic component. At first glance this is somewhat remarkable as many behavioral geneticists assert there are genetic components to all (or almost all) psychological constructs (Bouchard 2004; Bouchard and McGue 2003; Plomin and Defries 2016). The finding is even more remarkable given the general trend in behavioral genetics, where twin studies yield higher heritability estimates than do adoption and genome wide association studies (Collins et al. 2000). Reproducing our findings with these other designs common to behavioral genetics is thus unlikely to yield higher heritability estimates than the one presented here. 
Our findings are also relevant in the light of results from a recent behavioral genetics study in public administration indicating that sector affiliation had a heritable component (Christensen, Moon, and Whitford 2020). The fact that we find no heritable component of PSM suggests that the heritability of sector choice is not mediated by PSM. Future studies should investigate other mediators known to have genetic components, such as education (Branigan et al. 2013), personality (Vukasović and Bratko 2015), or intelligence (Devlin et al. 1997) to explore possible links between genetics and sector of employment.

As part of collecting data from the sample of twins, we were limited to a short four-item measure of PSM (Vandenabeele and DeVries 2016). We acknowledge that a multidimensional measure of PSM, such as Perry's (1996) or Kim et al.'s (2013) scales, would allow for an investigation into whether some subdimensions may be affected differently by genetics and socialization processes. This is an interesting question for future research, but one that we acknowledge will be practically difficult to address given the real constraints and challenges related to the design and reliance on twin pair samples.

The ACE model rests on theoretical and statistical assumptions that come with their own limitations (Neale and Cardon 1992). The assumption receiving the most attention is the "equal environment assumption" (EEA), which states that the common environment (C) influences MZ and DZ twins similarly. Critics of the classical twin design methodology argue that MZ (identical) twins are likely to be treated more similarly than their DZ (fraternal) counterparts since they look more alike. As a result, $\mathrm{MZ}$ twins will evoke more similar social responses from their environments (and from each other) (Medland and Hatemi 2009), in turn creating greater concordance on a characteristic or trait among MZ compared to their DZ counterparts (Charney 2008). 
There are three features of this study that alleviate concerns of a possible EEA violation. First, we directly test the effect of an EEA violation on our twin sample using an index of selfreport questionnaire items describing equal environmental treatment (see Appendix D). We first split the sample into three groups in accordance with their self-reported degree of equal treatment. We then calculate twin similarities for each of the three groups using separate ACE models. We find no discernable pattern in twin similarity across different degrees of equal treatment and, therefore, no evidence of a violation of the EEA affecting our results. In addition, the group high in equal treatment and the group low in equal treatment show almost the same degree of twin similarity in PSM. The difference in estimated MZ and DZ twin similarity between the two groups is only 0.008 - a negligible value. To further validate our results, we include the EEA-index as a moderator in our full ACE models and find no significant effects.

Second, research has found that MZ twins are treated more similarly in childhood than DZ twins in certain aspects, such as how they dress, sharing a room, and hair styles (Kendler et al. 1987). However, studies of greater relevance to the phenotype of interest here (PSM), suggest that the EEA is less relevant in describing differences in the social environments faced by MZ and DZ twins leading to political and ideological socialization and the development of social values. Hatemi et al. (2010), for example, leveraged a large set of extended kinships (parents, spouses, in-laws, non-twin siblings, and twin siblings) and found almost no difference between twin and non-twin sibling environments on the development of political ideology and attitudes. Smith et al. (2012) showed that factors likely to differ between MZ and DZ twins (e.g., sharing a room and style of clothing) had little to no effect on attitudinal, ideological, or partisanship similarity. Hatemi et al. (2009) offer the strongest evidence to date on the EEA. In a longitudinal study of MZ and DZ twin pairs aged 9-18 years old, the authors showed nearly identical co-twin 
correlations of political preferences throughout childhood. However, once the twins left home, DZ co-twin correlations of political preferences dropped, suggesting that home environment was responsible for the similarity between DZ co-twins. This observation is contrary to findings required to support a violation of the EEA. Thus, evidence from studies of attitudinal traits using other methods to examine the EEA assumption reach conclusions consistent with the evidence described above.

Third, critics of the EEA assumption and its validity argue, "(...) the evidence strongly suggested that the EEA — as it had been defined until then-was false. This indicated that conclusions in favor of genetics based on twin studies were confounded by environmental factors (...)" (Joseph 2014, p. 157) and that: “(...) researchers may be recording nothing more than MZ pairs' greater behavioral resemblance caused by their more similar environments, more similar treatment, and greater levels of emotional closeness and attachment." (Joseph 2014, p. 13). We agree with the principle that the EEA can be violated and we believe it should be evaluated on a trait by trait basis. However, this particular critique is not applicable in our case, as our study does not conclude in favor of genetics or record greater behavioral resemblance between MZ pairs. In other words, as a hypothetical breach to the EEA typically inflates the A-component and deflates the C-component in the ACE model, the lack of any substantial variance attributed to the A-component in our analysis limits the extent of the bias that can result from an EEA violation.

Another limitation often attributed to twin studies is that results may be population or sample specific and require multiple studies for generalization. This limitation is well-founded, as twin samples by their very nature are not random. However, Klemmensen et. al. (2012) compare the twin survey used in this study to a random sample of the Danish population on a host of political and social traits and find small or no significant differences in responses 
provided by twins and non-twins. Therefore, we do not expect issues of representativeness between twins and the broader public in our specific case. This should allow for a relatively unproblematic generalization of our results to the full population of Danes.

Finally, many modern interpretations of genetic effects on social phenomena rely on the notion of gene and environment interactions (Harden and Kollinger 2020), meaning that the effect of genes varies across environmental contexts. This is an interesting avenue for future research but is beyond the scope of the current study. We welcome future efforts to gain a more nuanced understanding of the complex interplay between genetic dispositions and environmental factors at play in shaping change and stability in PSM.

Despite the study's limitations, our findings have considerable implications. The null finding regarding PSM's genetic component is particularly important. First, the result offers support for PSM's unique contribution to understanding motivation beyond those offered by other prosocial constructs. This is important as critics have frequently pointed to PSM's failure to distinguish itself from altruism, empathy, and compassion (Bozeman and Su 2015). Most twin studies of "other-regarding" concepts show heritability (Warrier et al. 2018; Melchers et al. 2016). If PSM was purely redundant with these "other-regarding" concepts, we would expect it to also have a substantial genetic component. It can be argued that measures that rely less on the affective components of PSM might reflect the components of PSM that are truly unique and not redundant with other constructs. Examining our measure of PSM closely, it is perhaps more a reflection of the non-affective dimensions of PSM-the rational and instrumental-and emphasizes the desire to serve social institutions as opposed to individuals, the implications of which are now being considered in the literature (Piatak and Holt 2020) 
A second implication of this finding is the need for additional conceptual and theoretical work. Adopting an institutional perspective on PSM (Vandenabeele 2007) and focusing on the processes through which individuals develop and internalize rational and instrumental motives to serve institutions or collectives could offer a fresh perspective that focuses on the social processes that drive PSM's emergence. For instance, taking an approach to PSM that draws on a theory of motivation that is oriented towards members of social groups or collectives (not limited to their organizational identity) might prove productive (Tajfel et al. 1979). A second path is to explore other biological determinants of PSM. Evolutionary theories and perspectives are promising for two reasons. First, evolutionary theories are now being explored in relation to “other-regarding” phenomena (Nowak 2006; Van Vugt and Schaller 2008). Second, an evolutionary basis of bureaucratic behaviour has recently been re-introduced to the literature, therefore serving as a promising starting point for further theorizing (Smith and Renfro 2019).

Our study and results also help us reframe the "malleable state vs. stable trait" debate (Wright and Grant 2010). Since we are unable to detect any substantial genetic component to PSM, stability of the PSM concept and its manifestations is not based on heritability. This sets PSM apart from a wide variety of traits that have genetic components (Polderman et al. 2015). In contrast, two other sources of stability emerge. First, common environment is responsible for some, albiet minor variation in PSM. This suggests that common experiences shared by twins such as parental socialization could play a role in creating stability throughout an individual's life. Second, stability in individuals' PSM likely emerge as a results of stabilizing factors in the unique environment such as time-invariant features of one's workplace. Individuals might selfselect into environments that are conducive to their PSM, promoting stability in PSM over time. As such, efforts to classify PSM as either "stable" or "dynamic" miss the potential for a 
more complete understanding of the social processes that drive PSM. PSM should be acknowledged as a phenomenon with both stabilizing and malleable components, and the literature is perhaps better refocused on exploring which socialization mechanisms contribute to dynamic or stable construct behavior. Such a focus is perhaps best aimed at environments captured by the E component, such as workplace institutions and social influences. In this regard, we want to echo and expand upon the conclusion of Wright, Hassan and Christensen (2017) who write: "PSM can play an important role (...), but its effects need to be deliberately cultivated and nurtured rather than assumed or taken for granted." Stability in PSM itself must not be taken for granted as our results indicate that stability is most likely a result of environmental variables rather than individual-level predisposition. Therefore, a lack of a genetic component is important not just because it sets PSM apart from other related concepts, for instance personality (Van Witteloostuijn et al. 2017), but because it highlights how the environment and relevant actors such as managers or co-workers are likely the prime sources of both change and stability.

Rethinking the "trait vs. state" debate also allows for the unification of an empirical field with contradictory evidence on construct stability and malleability. Indeed, recent research demonstrates that PSM can, in fact, be activated and tapped as a resource for the organization (e.g., Jensen et al. 2019; Pedersen 2015) while other studies demonstrate relative stability in PSM values over time (Vogel and Kroll 2016). From our perspective, this is not a surprise nor are they problematic. Our empirical findings along with the rethinking of the debate is critical for the continued conceptual and theoretical advancement of PSM scholarship as it clearly identifies the origins of PSM. 


\section{REFERENCES}

Andersen, L. B., Heinesen, E., \& Pedersen, L. H. (2014). How does public service motivation among teachers affect student performance in schools? Journal of Public Administration Research and Theory, 24(3), 651-671. https://doi.org/10.1093/jopart/mut082

Batrićević, N., \& Littvay, L. (2017). A Genetic Basis of Economic Egalitarianism. Social Justice Research, 30(4), 408-437. https://doi.org/10.1007/s11211-017-0297-y

Blokland, G. A. M., Mosing, M. A., Verweij, K. J. H., \& Medland, S. E. (2013). Twin Studies and Behavior Genetics. In T. D. Little (Ed.), The Oxford Handbook of Quantitative Methods in Psychology: Vol. 2: Statistical Analysis (1st ed.). Oxford University Press.

Bouchard, T. J. (2004). Genetic influence on human psychological traits: A Survey. Current Directions in Psychological Science, 13(4), 148-151. https://doi.org/10.1111/j.09637214.2004.00295.x

Bouchard, T. J., \& McGue, M. (2003). Genetic and Environmental Influences on Human Psychological Differences. Journal of Neurobiology, 54(1), 4-45. https://doi.org/10.1002/neu.10160

Bozeman, B., \& Su, X. (2015). Public service motivation concepts and theory: A critique. Public Administration Review, 75(5), 700-710.

Branigan, A. R., Mccallum, K. J., \& Freese, J. (2013). Variation in the Heritability of Educational Attainment: An International Meta-Analysis. Social Forces, 92(1), 109-140.

Bright, L. (2005). Public Employees With High Levels of Public Service Motivation. Who Are They, Where Are They, and What do They Want? Review of Public Personnel Administration, 25(2): 138-154.

Charbonneau, É. \& Van Ryzin, G. G. (2017) Exploring the Deep Antecedent of Public Service Motivation, International Journal of Public Administration, 40(5), 401-407, DOI:

10.1080/01900692.2015.1126731

Charney, E. (2008). Genes and Ideologies. Perspectives on Politics, 6(2), 299-319. doi:10.1017/S1537592708080626

Christensen, R. K., Paarlberg, L., \& Perry, J. L. (2017). Public Service Motivation Research: Lessons for Practice. Public Administration Review, 77(4), 529-542. https://doi.org/10.1111/puar.12796

Christensen, R. K., Moon, K., \& Whitford, A. B. (2020). Genetics and sector of employment. International Public Management Journal, O(0), 1-11. https://doi.org/10.1080/10967494.2020.1802631

Clerkin, R. M., Paynter, S. R., \& Taylor, J. K. (2009). Public service motivation in undergraduate giving and Volunteering decisions. American Review of Public Administration, 39(6), 675-698. https://doi.org/10.1177/0275074008327512 
Collins, W. A., Maccoby, E. E., Steinberg, L., Hetherington, E. M., Bornstein, M. H., \& Universio, T. (2000). Contemporary Research on Parenting: The Case for Nature and Nurture. American Psychologist, 55(2), 218-232. https://doi.org/10.1037//0003-066X.55.2.218

Derks, Eske M., Conor V. Dolan, and Dorret I. Boomsma. (2006). "A test of the equal environment assumption (EEA) in multivariate twin studies." Twin Research and Human Genetics 9.3 403411.

Devlin, B., Daniels, M. \& Roeder, K. (1997). The heritability of IQ. Nature, 388, 468-471 https://doi.org/10.1038/41319

Enders, C. K. (2010). Applied Missing Data Analysis. Guilford Press.

Falconer, DS, MacKay TFC. (1996) Introduction to Quantitative Genetics, 4th Ed. Longmans Green, Harlow, Essex, UK.

Felson, J. (2014). "What can we learn from twin studies? A comprehensive evaluation of the equal environments assumption." Social science research 43 184-199.

Hamidullah, M. F., Van Ryzin, G. G., \& Li, H. (2016). The agreeable bureaucrat: personality and PSM. International Journal of Public Sector Management. 29(6), 582-595

Hatemi, P. K., Alford, J. R., Hibbing, J. R., Keller, M. C., Martin, N. G., Medland, S. E., \& Eaves, L. J. (2010). Not by Twins Alone: Using the Extended Twin Family Design to Investigate the Genetic Basis of Political Beliefs. American Journal of Political Science, 54(3), 798-814.

Hatemi, P. K., Funk, C. L., Medland, S. E., Maes, H. M., Silberg, J. L., Martin, N. G., \& Eaves, L. J. (2009). Genetic and environmental transmission of political attitudes over a life time. Journal of Politics, 71(3), 1141-1156. https://doi.org/10.1017/S0022381609090938

Hatemi, P., Medland, S., Klemmensen, R., Oskarrson, S., Littvay, L., Dawes, C., Verhulst, B., McDermott, R., Norgaard, A., Klofstad, C., Christensen, K., Johannesson, M., Magnusson, P., Eaves, L., \& Martin, N. (2014). Genetic Influences on Political Ideologies: Twin Analyses of 19 Measures of Political Ideologies from Five Democracies and Genome-Wide Findings from Three Populations. Behavioral Genetics, 44(3), 282-294. https://doi.org/10.1016/j.devcel.2010.12.007.

Harden, P., \& Koellinger, P. D. (2020) Using genetics for social science. Nature Human Behavior $4,567-576$

Houston, D. J. (2007). "Walking the walk" of public service motivation: Public employees and charitable gifts of time, blood, and money. Journal of Public Administration Research and Theory, 16(1), 67-86. https://doi.org/10.1093/jopart/mui028

Hvidtjørn, D., Petersen, I., Hjelmborg, J., Skytthe, A., Christensen, K., \& Hvidt, N. C. (2013). Familial resemblance in religiousness in a secular society: A twin study. Twin Research and Human Genetics, 16(2), 544-553. https://doi.org/10.1017/thg.2013.3

Israel, S., Hasenfratz, L., \& Knafo-Noam, A. (2015). The genetics of morality and prosociality. Current Opinion in Psychology, 6, 55-59. https://doi.org/10.1016/j.copsyc.2015.03.027 
Jensen, U. T., Andersen, L. B., \& Jacobsen, C. B. (2019). Only When We Agree! How Value Congruence Moderates the Impact of Goal-Oriented Leadership on Public Service Motivation. Public Administration Review, 79(1), 12-24. https://doi.org/10.1111/puar.13008

Jensen, U. T., \& Bro, L. L. (2018). How transformational leadership supports intrinsic motivation and public service motivation: The mediating role of basic need satisfaction. The American Review of Public Administration, 48(6), 535-549.

Jensen, U. T., Kjeldsen, A. M., \& Vestergaard, C. F. (2020). How Is Public Service Motivation Affected by Regulatory Policy Changes?. International Public Management Journal, 23(4), $465-495$.

Jensen, U. T., \& Vestergaard, C. F. (2017). Public service motivation and public service behaviors: Testing the moderating effect of tenure. Journal of Public Administration Research and Theory, 27(1), 52-67.

Joseph, J. (2014). The Trouble with Twin Studies: A Reassessment of Twin Research in the Social and Behavioral Sciences. Routledge.

Kendler, K. S., Heath, A.C., Martin, N.G., and Eaves. L.J. (1987). "Symptoms of Anxiety and Symptoms of Depression. Same Genes, Different Environments?”. Archives of General Psychiatry, 44(5): 451-57.

Kim, S. (2020) Education and Public Service Motivation: A Longitudinal Study of High School Graduates Public Administration Review.

Kim, S., Vandenabeele, W., Wright, B. E., Andersen, L. B., Cerase, F. P., Christensen, R. K., ... \& Palidauskaite, J. (2013). Investigating the structure and meaning of public service motivation across populations: Developing an international instrument and addressing issues of measurement invariance. Journal of Public Administration Research and Theory, 23(1), 79-102.

Kjeldsen, A. M. (2014). Dynamics of public service motivation: Attraction-selection and socialization in the production and regulation of social services. Public Administration Review, 74(1), 101-112.

Klemmensen, R., Hatemi, P. K., Hobolt, S. B., Petersen, I., Skytthe, A., \& Nørgaard, A. S. (2012). The genetics of political participation, civic duty, and political efficacy across cultures: Denmark and the United States. Journal of Theoretical Politics, 24(3), 409-427. https://doi.org/10.1177/0951629812438984

Koenig, L. B., McGue, M., Krueger, R. F., \& Bouchard, T. J. (2007). Religiousness, antisocial behavior, and altruism: Genetic and environmental mediation. Journal of Personality, 75(2), 265-290. https://doi.org/10.1111/j.1467-6494.2007.00439.x

Lewis, G. J., \& Bates, T. C. (2011). A common heritable factor influences prosocial obligations across multiple domains. Biology Letters, 7(4), 567-570. https://doi.org/10.1098/rsbl.2010.1187

Loehlin, J., \& Nichols, R. (1976). Heredity, environment and personality. Austin \& London: University of Texas Press.

Medland, S. E., \& Hatemi, P. K. (2009). Political science, biometric theory, and twin studies: A methodological introduction. Political Analysis, 191-214. 
Melchers, M., Montag, C., Reuter, M., Spinath, F. M., \& Hahn, E. (2016). How heritable is empathy? Differential effects of measurement and subcomponents. Motivation and Emotion, 40(5), 720-730. https://doi.org/10.1007/s11031-016-9573-7

Moffitt, T. E. (2005). Genetic and Environmental Influences on Antisocial Behaviors: Evidence from Behavioral-Genetic Research. Advances in Genetics, 55(05), 41-104.

https://doi.org/10.1016/S0065-2660(05)55003-X

Morrow, P. C. (1983). Concept redundancy in organizational research: The case of work commitment. Academy of management Review, 8(3), 486-500.

Moynihan, D. P., \& Pandey, S. K. (2007). The role of organizations in fostering public service motivation. Public Administration Review, 67(1), 40-53.

Neale, M. C., \& Cardon, L. R. (1992). NATO ASI series D: Behavioural and social sciences, Vol. 67.Methodology for genetic studies of twins and families. Kluwer Academic/Plenum Publishers. https://doi.org/10.1007/978-94-015-8018-2

Nofal, A. M., Nicolaou, N., Symeonidou, N., \& Shane, S. (2018). Biology and Management: A Review, Critique, and Research Agenda. Journal of Management, 44(1), 7-31. https://doi.org/10.1177/0149206317720723

Nowak, M. A. (2006). Five rules for the evolution of cooperation. Science, 314(5805), 1560-1563. https://doi.org/10.1126/science.1133755.Five

Pandey, S. K., \& Stazyk, E. C. (2008). Antecedents and correlates of public service motivation. Motivation in public management: The call of public service, 101-117.

Pedersen, M. J. (2015). Activating the forces of public service motivation: Evidence from a lowintensity randomized survey experiment. Public Administration Review, 75(5), 734-746.

Pedersen, O. B., Axel, S., Rostgaard, K., Erikstrup, C., Edgren, G., Nielsen, K. R., Ullum, H., Kyvik, K. O., \& Hjalgrim, H. (2015). The heritability of blood donation: A population-based nationwide twin study. Transfusion, 55(9), 2169-2174. https://doi.org/10.1111/trf.13086

Pedersen D.A., Larsen L. A., Nygaard M., Mengel-From J., McGue M., Dalgård C., Hvidberg L., Hjelmborg J., Skytthe A., Holm N. V., Kyvik K. O., Christensen K. (2019). The Danish Twin Registry: An updated overview. Twin Research and Human Genetics, 22(6):499-507

Perry, J. L., \& Wise, L. R. (1990). The Motivational Bases of Public Service. Public Administration Review, 50(3), 367-373.

Perry, J. L. (1996). Measuring public service motivation: An assessment of construct reliability and validity. Journal of Public Administration Research and Theory, 6(1), 5-22.

Perry, J. L. (1997). Antecedents of public service motivation. Journal of Public Administration Research and Theory, 7(2), 181-197.

Perry, J. L., Brudney, J. L., Coursey, D., \& Littlepage, L. (2008). What drives morally committed citizens? A study of the antecedents of public service motivation. Public Administration Review, 68(3), 445-458. 
Perry, J. L., \& Vandenabeele, W. (2008). Behavioral dynamics: Institutions, identities, and selfregulation. Motivation in public management: The call of public service, 56-79.

Piatak, J. S., \& Holt, S. B. (2020). Prosocial Behaviors: A Matter of Altruism or Public Service Motivation?. Journal of Public Administration Research and Theory, 30(3), 504-518.

Plomin, R. (1990). The Role of Inheritance in Behavior. Science, 248(4952), 183-188.

Plomin, R., \& Asbury, K. (2005). Nature and Nurture: Genetic and Environmental Influences on Behavior. The Annals of the American Academy of Political and Social Science, 600, 86-98. https://doi.org/10.1177/0002716205277184

Plomin, R., \& Daniels, D. (1987). Children in the same family are very different, but why? Behavioral and Brain Sciences, 10(1), 1-16.

Plomin, R., \& Defries, J. C. (2016). Europe PMC Funders Group Top 10 Replicated Findings from Behavioral Genetics. Perspectives on Psychological Science, 11(1), 3-23. https://doi.org/10.1177/1745691615617439.Top

Polderman, T. J. C., Benyamin, B., De Leeuw, C. A., Sullivan, P. F., Van Bochoven, A., Visscher, P. M., \& Posthuma, D. (2015). Meta-analysis of the heritability of human traits based on fifty years of twin studies. Nature Genetics, 47(7), 702-709. https://doi.org/10.1038/ng.3285

Powledge, T. M. (1993). The inheritance of behavior in twins. BioScience, 43(7), 420-424.

Purcell, Shaun. "Variance components models for gene-environment interaction in twin analysis." Twin Research and Human Genetics 5.6 (2002): 554-571.

Ritz, A., Brewer, G. A., \& Neumann, O. (2016). Public Service Motivation A Systematic Literature Review and Outlook. Public Administration Review, 76(3), 414-426. https://doi.org/10.1111/puar.12505.for

Rushton, J. P., Fulker, D. W., Neale, M. C., Nias, D. K. B., \& Eysenck, H. J. (1986). Altruism and Aggression. The Heritability of Individual Differences. Journal of Personality and Social Psychology, 50(6), 1192-1198. https://doi.org/10.1037/0022-3514.50.6.1192

Rutter, M. (2002). Nature, Nurture, and Development: From Evangelism through Science toward Policy and Practice. Child Development, 73(1), 1-21.

Schott, C., Neumann, O., Baertschi, M., \& Ritz, A. (2019). Public Service Motivation, Prosocial Motivation and Altruism: Towards Disentanglement and Conceptual Clarity. International Journal of Public Administration, 42(14), 1200-1211. https://doi.org/10.1080/01900692.2019.1588302

Segal, N. (2010) Twins: The finest natural experiment. Personality and Individual Differences 49(4), 317-323

Smith, K., Alford, J. R., Hatemi, P. K., Eaves, L. J., Funk, C., \& Hibbing, J. R. (2012). Biology, ideology, and epistemology: How do we know political attitudes are inherited and why should we care? American Journal of Political Science, 56(1), 17-33. https://doi.org/10.1111/j.1540$\underline{5907.2011 .00560 . x}$ 
Smith, K. B., \& Renfro, J. L. (2019). Darwin's bureaucrat: Reassessing the microfoundations of bureaucracy scholarship. Politics and the Life Sciences, 38(2), 168-179.

Son, J., \& Wilson, J. (2010). Genetic Variation in Volunteerism. The Sociological Quarterly, 51(1), 46-64.

Stritch, J. M., \& Christensen, R. K. (2016). Raising the next generation of public servants? Parental influence on volunteering behavior and public service career aspirations. International Journal of Manpower, 37(5), 840-858. doi:doi:10.1108/IJM-12-2014-0249

Tajfel, H., Turner, J. C., Austin, W. G., \& Worchel, S. (1979). An integrative theory of intergroup conflict. Organizational identity: A reader, 56, 65.

Vandenabeele, W. (2007). Toward a public administration theory of public service motivation: An institutional approach. Public management review, 9(4), 545-556.

Vandenabeele, W. (2011). Who Wants to Deliver Public Service? Do Institutional Antecedents of Public Service Motivation Provide an Answer? Review of Public Personnel Administration, 31(1), 87-107. doi:10.1177/0734371x10394403

Vandenabeele, W., Brewer, G. A., \& Ritz, A. (2014). Past, present, and future of public service motivation research. Public Administration, 92(4), 779-789. https://doi.org/10.1111/padm.12136

Vandenabeele, W., \& De Vries, J. P. (2016). A Global Measure of Public Service Motivation: Comparing a Global Scale of PSM to the Kim et al Measure. Annual 2016 IRSPM Conference, 35-40. https://doi.org/10.1109/ciced.2018.8592188

Van Vugt, M., \& Schaller, M. (2008). Evolutionary Approaches to Group Dynamics: An Introduction. Group Dynamics: Theory, Research, and Practice, 12(1), 1-6. https://doi.org/10.1037/1089-2699.12.1.1

Van Witteloostuijn, A., Esteve, M., \& Boyne, G. (2017). Public sector motivation ad fonts: Personality traits as antecedents of the motivation to serve the public interest. Journal of Public Administration Research and Theory, 27(1), 20-35.

Vogel, D., \& Kroll, A. (2016). The stability and change of PSM-related values across time: Testing theoretical expectations against panel data. International Public Management Journal, 19(1), 5377.

Vukasović, T., \& Bratko, D. (2015). Heritability of Personality: A Meta-Analysis of Behavior Genetic Studies. Psychological Bulletin, 141(4), 769-785. https://doi.org/10.1037/bul0000017

Warrier, V., Grasby, K. L., Uzefovsky, F., Toro, R., Smith, P., Chakrabarti, B., Khadake, J., Mawbey-Adamson, E., Litterman, N., Hottenga, J. J., Lubke, G., Boomsma, D. I., Martin, N. G., Hatemi, P. K., Medland, S. E., Hinds, D. A., Bourgeron, T., \& Baron-Cohen, S. (2018). Genome-wide meta-analysis of cognitive empathy: Heritability, and correlates with sex, neuropsychiatric conditions and cognition. Molecular Psychiatry, 23, 1402-1409. https://doi.org/10.1038/mp.2017.122

Wright, B. E., \& Christensen, R. K. (2010). Public service motivation: A test of the job attractionselection-attrition model. International Public Management Journal, 13(2), 155-176. https://doi.org/10.1080/10967491003752012 
Wright, B. E., Christensen, R. K., \& Pandey, S. K. (2013). Measuring public service motivation: Exploring the equivalence of existing global measures. International Public Management Journal, 16(2), 197-223.

Wright, B. E., \& Grant, A. M. (2010). Unanswered Questions about Public Service Motivation: Designing Research to Address Key Issues of Emergence and Effects. Public Administration Review, 70(5), 691-700.

Wright, B. E., Hassan, S., \& Christensen, R. K. (2017). Job choice and performance: Revisiting core assumptions about public service motivation. International Public Management Journal, 20(1), 108-131

Wright, B. E., Moynihan, D. P., \& Pandey, S. K. (2012). Pulling the levers: Transformational leadership, public service motivation, and mission valence. Public Administration Review, 72(2), 206-215.

Figure legends and explanatory text:

Figure 1: ACE SEM Path Coefficients Model

*The rectangular boxes refer to the phenotypic traits investigated in a twin pair. The ACE component refer to latent variables in the SEM parlace. The a, c, and e parameters are the estimated path coefficients and the correlations between the $\mathrm{A}$ and $\mathrm{C}$ are constrained to be 1 for the shared environment and 1 for $\mathrm{MZ}$ twins ( 0.5 for $\mathrm{DZ}$ twins). 
Table 1. Descriptive Statistics for Twin Pairs in Study Sample

\begin{tabular}{|c|c|c|c|c|}
\hline Zygosity & PSM & Gender & Age & No. of Twin Pairs \\
\hline Monozygotic (MZ) & $0.50(0.12)$ & $0.38(0.49)$ & $30.28(5.87)$ & 557 \\
\hline Dizygotic (DZ) & $0.49(0.13)$ & $0.42(0.49)$ & $28.71(6.24)$ & 478 \\
\hline
\end{tabular}

Notes: All variables, except age, are rescaled to range between zero and one. Numbers refer to means with standard deviations in parentheses. Only twin pairs with data on all variables are included in this table. 
Table 2. Twin Correlations

\begin{tabular}{|c|c|}
\hline Group & Twin Correlations \\
\hline Monozygotic (MZ) & 0.046 \\
\hline Dizygotic (DZ) & 0.072 \\
\hline
\end{tabular}


Table 3: ACE Model for Public Service Motivation (PSM)

\begin{tabular}{|c|c|c|}
\hline Variance Component & Estimate & P-value \\
\hline A & $0.097(0.176)$ & 0.582 \\
\hline C & $0.165(0.314)$ & 0.600 \\
\hline E & $0.966(0.026)$ & 0.000 \\
\hline
\end{tabular}

Notes: $\mathrm{A}=$ Additive genetics, $\mathrm{C}=\mathrm{Common}$ environment shared by co-twins, and $\mathrm{E}=$ Unique environment and experiences that is not shared by co-twins. Standard error in parentheses. 
Table 4: CE model for Public Service Motivation (PSM)

\begin{tabular}{|c|c|c|}
\hline Variance Component & Estimate & P-value \\
\hline C & $0.233(0.108)$ & 0.031 \\
\hline E & $0.970(0.023)$ & 0.000 \\
\hline
\end{tabular}


Appendix A: Item wording in PSM construct

\begin{tabular}{l|l}
\hline English version & Danish version \\
\hline I am very motivated to contribute to society & $\begin{array}{l}\text { Jeg er stærkt motiveret for at bidrage til } \\
\text { samfundet. }\end{array}$ \\
\hline $\begin{array}{l}\text { I find it very motivating to contribute to } \\
\text { society }\end{array}$ & $\begin{array}{l}\text { Jeg finder det stærk motiverende at bidrage til } \\
\text { samfundet }\end{array}$ \\
\hline $\begin{array}{l}\text { Making a difference in society, no matter how } \\
\text { small, is very important to me }\end{array}$ & $\begin{array}{l}\text { At gøre en forskel for samfundet er vigtigt for } \\
\text { mig, uanset om den er lille. }\end{array}$ \\
\hline $\begin{array}{l}\text { Defending the public interest is very } \\
\text { important to me }\end{array}$ & $\begin{array}{l}\text { Beskyttelse af offentlige interesser er meget } \\
\text { vigtigt for mig. }\end{array}$ \\
\hline
\end{tabular}

The questions were translated from the English version of Vandenabeele and DeVries (2016) into Danish for the survey. Back translation was not employed. 
Appendix B: Information on missing values, attrition and multiple imputation

This appendix describes how we handled missing data and an assessment of representativeness from Wave 1 to Wave 3. In the literature on missing data, it is customary to distinguish between unit-nonresponse (a person does not answer the survey which is sent out) and item-non response (a survey respondent does not answer a single item in the survey). We use multiple imputation to handle both of these concerns in a standard way commonly used to deal with missing values (Enders, 2010).

There are two main principles guiding the approach towards missing data. We deal with attrition by using the fact that our data was collected as part of a panel study with three waves. However, we only use the first and the third wave in this study. First, the Wave 1 of the twin survey collected in 2009 is highly representative of the Danish population (Klemmensen et. al., 2012) and we want to make sure Wave 3 data collected in 2019 are not falling short of this because of attrition. Second, we want to use all available data and not waste information. Wave 1 data has, as shown below, more full twin pairs, and complete information on gender, age, and region; and almost full information on education as well. We use this information to address attrition.

Below are three tables to give an idea of the amount of missing values in the data, and the differences in basic descriptive statistics among the two waves of data used in the study. In Table B2.1, we can see that there are no major differences in gender and age across the two samples. The difference in age between the waves is mostly caused by the eight year difference between the two collections.

Table B2.1: Descriptive statistics for the two waves of data used

\begin{tabular}{lllll}
\hline \hline Wave & Mean age & $\begin{array}{l}\text { Standard deviation } \\
\text { age }\end{array}$ & Mean gender & $\begin{array}{l}\text { Standard deviation } \\
\text { gender }\end{array}$ \\
1 & 29.5 & 6.11 & 0.400 & 0.490 \\
3 & 40.3 & 5.98 & 0.382 & 0.486 \\
\hline \hline
\end{tabular}

In Table B2.2, we can see that there is a fair amount of attrition from Wave 1 to Wave 3 (i.e. roughly 641 fewer people answered the third survey compared to the first. There are also, among those who responded, a couple of people who did not answer the full set of PSM items, but not many.

Table B2.2: Descriptive statistics for attrition, and missing values in the two waves used

\begin{tabular}{lllllll}
\hline \hline Wave & Total $n$ & $\begin{array}{l}\text { Non- } \\
\text { respondents }\end{array}$ & $\begin{array}{l}\text { Total } \\
\text { respondents }\end{array}$ & $\begin{array}{l}\text { Missing values for } \\
\text { PSM } \\
\text { among those who } \\
\text { responded }\end{array}$ & $\begin{array}{l}\text { MZ/DZ pairs } \\
\text { among those who } \\
\text { responded }\end{array}$ & $\begin{array}{l}\text { Complete } \\
\text { MZ/DZ pairs } \\
\text { among those } \\
\text { who responded }\end{array}$ \\
1 & 4911 & 2174 & 2737 & - & $839 / 935$ & $511 / 542$ \\
3 & 2875 & 1533 & 1342 & 39 & $519 / 478$ & $195 / 141$ \\
\hline \hline
\end{tabular}


In Table B2.3, the Wave 3 collection is not highly different from the Wave 1 data collection in terms of geographical dispersion.

Table B2.3: Descriptive statistics for "landsdel" (part of the country) in the two waves used

\begin{tabular}{|c|c|c|}
\hline Landsdel & Proportion Wave 1 & Proportion Wave 2 \\
\hline Landsdel Bornholm & 0.003 & 0.002 \\
\hline Landsdel Byen København & 0.225 & 0.221 \\
\hline Landsdel Fyn & 0.088 & 0.079 \\
\hline Landsdel Kobenhavns omegn & 0.076 & 0.079 \\
\hline Landsdel Nordjylland & 0.094 & 0.098 \\
\hline Landsdel Nordsjalland & 0.056 & 0.061 \\
\hline Landsdel Sydjylland & 0.116 & 0.118 \\
\hline \multicolumn{3}{|l|}{ Landsdel Vest- og } \\
\hline Sydsjaelland & 0.076 & 0.065 \\
\hline Landsdel Vestjylland & 0.072 & 0.074 \\
\hline Landsdel Østjylland & 0.173 & 0.168 \\
\hline Landsdel $\emptyset_{\text {stsjaelland }}$ & 0.022 & 0.022 \\
\hline
\end{tabular}

If we do not use multiple imputation to estimate missing data, we rely on the assumption of data missing completely at random (MCAR). This is often unrealistic since we know that females are often more likely to answer surveys and younger people are also less likely to answer a survey. Estimating missing data relies on the somewhat less restrictive missing at random (MAR) assumption. The MAR assumption is "when the probability of missing data on a variable $\mathrm{Y}$ is related to some other measured variable (or variables) in the analysis model but not to the values of Y itself" (Enders 2010, p. 6). This is less restrictive than the MCAR assumption.

A more complete walk through of multiple imputation can be found in Chapter 6-10 in (Enders, 2010). The basic idea is quite simple though. We use predictors we know are related to missing data. Here we include age, gender, zygosity, levels of primary schooling, levels of higher education, region of country ("landsdel") and the PSM score in the imputation process. We then create a series of datasets (in our case 20) that include randomness across the realizations. When we conduct the analyses, we run the analyses on all datasets and average the results.

In order to deal with attrition and item non-response for PSM, we use multiple imputation as implemented in Mplus version 8. Before the final multiple imputation, autocorrelation plots were used to investigate at which points the data become independent. Based on this, we determined 
that 300 between-imputations were sufficient to get independent datasets. We use the default settings in Mplus for convergence and created 20 datasets. 


\section{Appendix C:}

Twin modeling is usually performed within a structural equation modeling (SEM) framework. SEM allows for building more advanced models with controls such as age and sex, and facilitates dealing with missing data in more appropriate ways. While we perform univariate twin modeling in our analysis, a SEM model might be used to estimate the covariances between multiple phenotypes and estimate more complex relationships.

In the SEM framework, the ACE components can be viewed as latent variables. In the simple form without controls or additional constraints based on gender, the ACE model can be estimated with a multiple group analysis (i.e. DZ and MZ twin pairs). Since MZ twins share 100 percent of their segregating genes, we constrain the twin pairs genetic correlation to be 1 . Since DZ twins share 50 percent of their segregating genes, we constrain their genetic correlation to be 0.5 . For both $\mathrm{MZ}$ and $\mathrm{DZ}$ twins, we constrain the common environment $(\mathrm{C})$ to have a correlation of 1 since the shared environment is assumed to be shared equally for both MZ and DZ twins. The unique environment (E) is by definition not shared, so we do not impose a constraint on the within twin-pair PSM correlation. To identify the model, we constrain the latent variables to have a variance of 1 and a mean of zero, but allow the paths from the latent variables (ACE) on PSM to be freely estimated. This way of parameterizing the model is called a path coefficients model (Neale and Cardon 1992). All coefficients presented in the results section are standardized coefficients. Since the coefficients represent standardized path coefficients we can, as in any latent variable model, estimate the variance explained by simply squaring them. All estimations are performed in Mplus version 7 using robust standard errors. This path coefficients model is displayed in Figure 1. 
Appendix D: Test of the EEA assumption.

We know from the classical study by Lohelin and Nicols (1976) that MZ twins in childhood more often share the same room and dress more alike than DZ twins, which suggests the environment of MZ twins is more equal than that of DZ twins. This is potentially problematic since the estimation of heritability, and of the shared environmental effects, rests on the assumption that twins are treated equally - the so-called Equal Environment Assumption (EEA).

There have been quite a few attempts at investigating the EEA across different areas and most studies find little to no violation of the assumption (Felson, 2014). Most relevant for this study are the studies of political and social attitudes, which find little to no violation of the EEA (Hatemi et al, 2010, Smith et al, 2012, Hatemi et al, 2009).

Of course we cannot rule out the possibility that the EEA is violated for PSM specifically (Joseph, 2014: Chapter 7) since we are unaware of any study investigating the EEA for this particular construct. We therefore conduct two tests of the EEA with regards to PSM. Before diving into these, it is worth highlighting that our study has found a substantial amount of non-shared environmental influences and some common environmental influences on PSM. The EEA only biases results for the estimation of genetic and common environmental influences on a construct (Derks, et al, 2006). Typically, critics have argued that the EEA inflates estimates of genetic influences (Joseph, 2014: Chapter 7). Since we find no significant A componet, the bias in our results, if any, only concern our estimation of shared environmental influences.

We use twin's self-reports of childhood degree of equal environments which is arguably preferable to using the self-reported reports from parents since this approach has been criticized on account of parents not being able to acknowledge their differential treatment of their children (Felson, 2014). We use these items to measure environmental similarity among co-twins:

- We shared a room

- We had the same friends

- We were similarly dressed

- We had the same past time activities

- Our parents treated us similarly

The scale had these answer categories: Always, often, at times, rarely and never. Based on these questions we constructed a combined scale, which had an alpha reliability of 0.64 . We use this scale to conduct two analyses. First we simply split the sample into three equally sized groups and replicate the main analyses of the paper (i.e. a full ACE model, separately for each group). We then compare the estimated twin correlations from each group. If we find that the MZ correlations are increasing systematically when our EEA measure increases this suggests that the EEA is violated. The results of this investigation are shown in the table below:

Table C3.1: MZ/DZ correlations as a function of self-reported EEA

\begin{tabular}{|l|l|l|}
\hline & $\begin{array}{l}\text { MZ } \\
\text { correlations }\end{array}$ & $\begin{array}{l}\text { DZ } \\
\text { correlations }\end{array}$ \\
\hline High EEA & 0.069 & 0.036 \\
\hline Medium EEA & 0.041 & 0.041 \\
\hline Low EEA & 0.114 & 0.085 \\
\hline
\end{tabular}


The correlations vary somewhat but there is no indication that the MZ correlations increase. In fact, the MZ correlations are highest when the self-reported measure of EEA is lowest. Using Falconer's formula our measure of heritability is 0.066 when EEA is highest and 0.058 when it is lowest.

Our second analysis is a formal moderation model. A full explanation can be found in Purcell (2002). Briefly stated, the variance components are, much like in a linear regression, allowed to vary as a function of our moderator, which in this case is our self-reported measure of EEA. So instead of estimating these the variance unconditionally:

$$
T^{2}=a^{2}+c^{2}+e^{2}
$$

We let the variance be a function of our moderator and estimate this equation instead:

$$
T^{2}=\left(a+\beta_{M_{a}}\right)^{2}+\left(c+\beta_{M_{c}}\right)^{2}+\left(e+\beta_{M_{e}}\right)
$$

Just as in ordinary least squares regression, we can then test for a moderating effect by testing the significance of the interaction terms (i.e. $\beta_{M_{a}}, \beta_{M_{c}}, \beta_{M_{e}}$ ). The results of this model specification are shown in the table below:

Table C3.2: Results for moderation model to test the appropriateness of the EEA assumption for PSM.

\begin{tabular}{|c|c|}
\hline Parameter & $\begin{array}{c}\text { Estimate } \\
\text { (standard error) }\end{array}$ \\
\hline $\mathrm{a}$ & 0.027 \\
& $(0.089)$ \\
\hline $\mathrm{c}$ & 0.031 \\
& $(0.109)$ \\
\hline $\mathrm{e}$ & $0.162 *$ \\
& $(0.020)$ \\
\hline$\beta_{M_{a}}$ & -0.005 \\
& $(0.036)$ \\
\hline$\beta_{M_{c}}$ & -0.005 \\
& $(0.044)$ \\
\hline$\beta_{M_{e}}$ & 0.002 \\
& $(0.008)$ \\
\hline
\end{tabular}

* Indicates the coefficient is significant at a .05 level. The results are unstandardized results since standardized results can be difficult to interpret in this moderation model (see Purcell 2002).

As Table C3.2 illustrates, none of the interaction terms are close to being significant and, thus, we do not find any support for potential problems of equal environments using self-reported measures of childhood similarity when estimating ACE components for PSM. 